\title{
The influence of bracket type on the external apical root resorption in class I extraction patients - a retrospective study
}

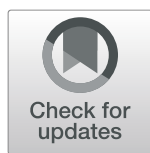

Fang Qin ${ }^{1}$ and Yu Zhou ${ }^{2 *}$

\begin{abstract}
Background: The relationship between orthodontic treatment-related factors and EARR has never been fully answered. The aim of this study was to investigate whether conventional and passive self-ligating brackets affect the amount and severity of external apical root resorption (EARR) in withdrawal patients.

Methods: Ninety-eight patients were selected from department of orthodontic, hospital of stamotology, Wenzhou medical university. Patients received treatment with either a conventional edgewise appliance $(n=49$, Mini, $3 \mathrm{M}$ Unitek, USA) or a passive self-ligating bracket system ( $n=49$, Damon, Ormco, USA). EARR of the maxillary incisors was evaluated on panoramic radiographs at the before and end of orthodontic treatment, respectively. Intergroup comparisons of root resorption were performed with Mann-Whitney tests. The univariate and multivariate regression model was used to assess the appliance type, age, sex and duration of treatment on EARR.
\end{abstract}

Results: There was no significant difference in the amount of EARR between the two groups was found. Age and gender were not association with EARR, however, EARR was positively correlated with treatment duration.

Conclusions: The type of bracket did not influence the occurrence and severity of the external apical root resorption in class I extraction patients.

Keywords: External apical root resorption, Passive self-ligating, Orthodontic, Conventional bracket

\section{Background}

External apical root resorption (EARR) which defined as shortening or blunting of the root apex is considered as one of most serious adverse effect in orthodontic treatment [1]. The teeth of maxillary incisors are most prone to EARR [2].

However, the relationship between orthodontic and EARR has never been fully answered. Many factors, such as type of force application, treatment duration, force magnitudes and the distance of tooth movement, maybe contribute to the incidence and severity of EARR during orthodontic treatment [3-7].

In recently, many studies have come to a conclusion that mechanical forces play a key role in the occurrence of EARR during orthodontic treatment [8]. However, by

\footnotetext{
* Correspondence: 156089794@qq.com

2Department of Orthodontic, School and Hospital of Stomatology, Wenzhou Medical University, Wenzhou, Zhejiang, China

Full list of author information is available at the end of the article
}

now there were only few studies have assessed the effects of brackets type on EARR [9-12]. Self-ligating brackets have been gaining popularity in recent years which was first introduced in the early 1930s [11]. These brackets claimed advantages of shorter treatment time, less friction and a higher rate of teeth movement. Because of so many advantages, a hypothesis has been raised as to their effect on EARR. But, the occurrence of EARR between conventional and passive self-ligating brackets has not yet been fully investigated. In the orthodontic literatures, there are few studies have explored the influence of self-ligating brackets on EARR [9-12]. Previous studies found that no significant difference regarding the occurrence of EARR between conventional and passive self-ligating brackets. However most of these studies shortage were a small amount of patients or with different treatment plan [9-12]. As I known, this is the first study which only included extraction patient to assess the amount and severity of external apical root

(C) The Author(s). 2019 Open Access This article is distributed under the terms of the Creative Commons Attribution 4.0 International License (http://creativecommons.org/licenses/by/4.0/), which permits unrestricted use, distribution, and 
Table 1 Inclusion and exclusion criteria in two groups

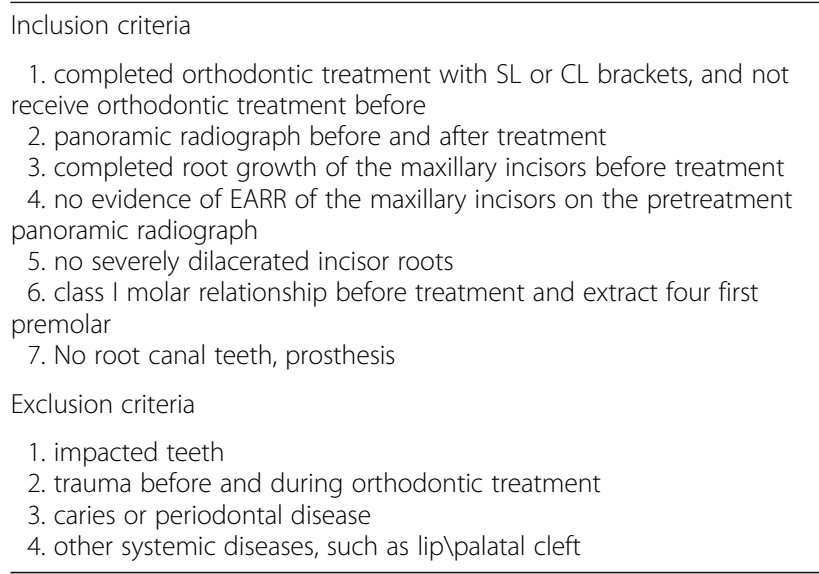

resorption. Thus, the purpose of this study was to investigate the incidence of EARR on maxillary incisors in extraction patients treated with conventional brackets and passive self-ligating brackets. We furthermore analyze the influence of age, gender and treatment time on the occurrence of EARR.

\section{Materials and methods \\ Patients}

According to the previous study, in order to detect a significant change in root resorption we need a sample size of 42 subjects, with an $80 \%$ probability power at the $5 \%$ level of significance.

In this retrospective study, 98 participants were selected from 489 patients who completed the orthodontic treatment in the Department of orthodontic, hospital of stomatology, Wenzhou Medical University. They were divided into two groups: passive self-ligating brackets group (Damon 3, OMRCO, USA) and conventional brackets group (3 M Unitek, California, USA). The inclusion and exclusion criteria see Table 1. The demographics of these subjects are listed in Table 2.

\section{Treatment procedure}

The archwire sequence was 0.012-in, 0.016-in and $0.019 \times 0.025$-in copper- nickel-titanium (Ormco) and

Table 2 Demographic and clinical characteristics of the patients in two groups

\begin{tabular}{|c|c|c|c|c|c|}
\hline \multirow{2}{*}{$\begin{array}{l}\text { Characteristics } \\
\text { Age }\end{array}$} & \multicolumn{2}{|c|}{$\begin{array}{l}\text { Conventional } \\
\text { (mean and SD) }\end{array}$} & \multicolumn{2}{|c|}{$\begin{array}{l}\text { Self-ligating } \\
\text { (mean and SD) }\end{array}$} & \multirow{2}{*}{$\begin{array}{l}P \text { value } \\
\text { NS }\end{array}$} \\
\hline & 15.21 & 4.43 & 15.15 & 4.52 & \\
\hline \multicolumn{6}{|l|}{ Sex } \\
\hline Female & 23 & & 24 & & \\
\hline Male & 26 & & 25 & & NS \\
\hline Treatment duration (mo) & 22.10 & 5.15 & 20.25 & 5.11 & NS \\
\hline
\end{tabular}

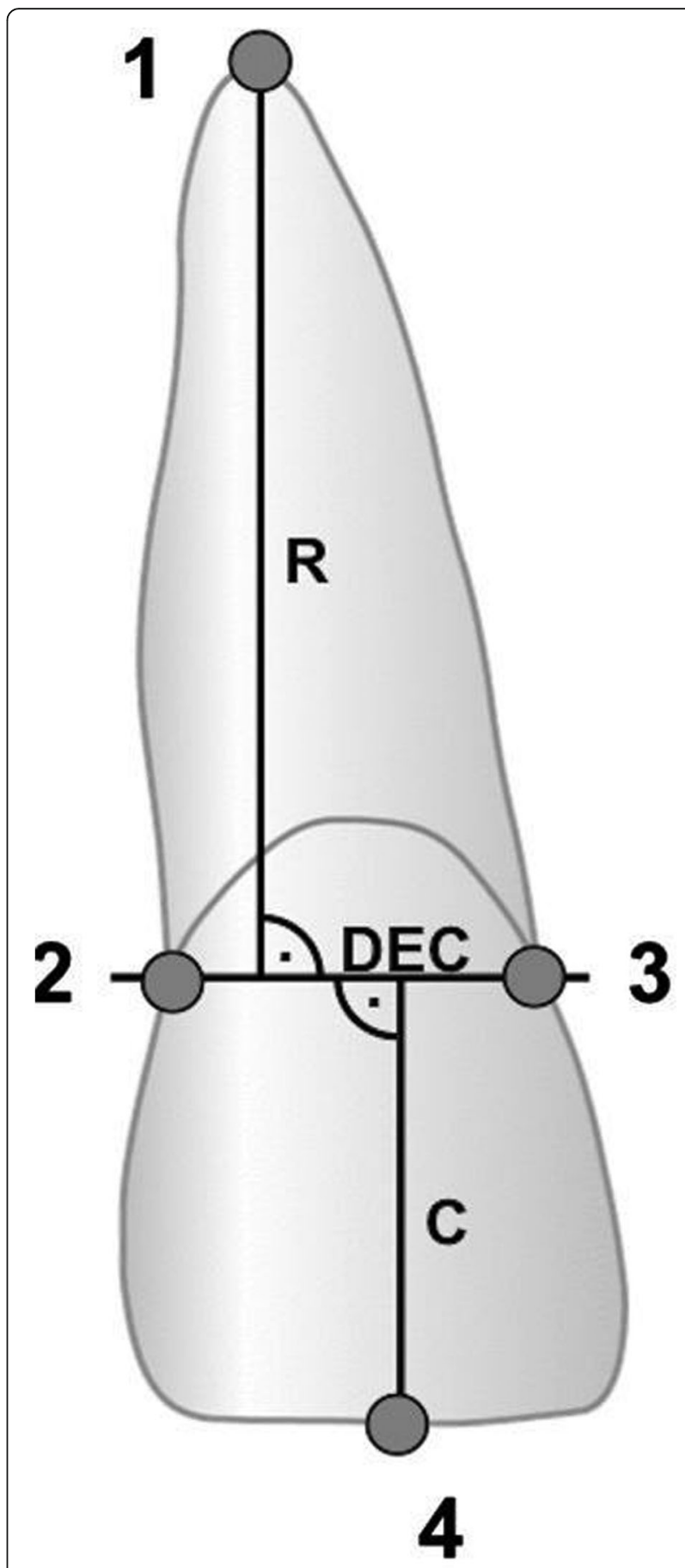

Fig. 1 X-ray measurement of root resorption. Reference points:1 root apex,2 distal dento-enamel junction,3 mesial dento-enamel junction,4 incisal edge. Dento-enamel conjunction (DEC) represents the conjunction between mesial and distal. Crown length $(C)$ and root length(R) were measured perpendicular to DEC as the longest distance to the root apex and the incisal edge. This figure first describe by Jacobs et al. Head \& face medicine 2014,10:2 

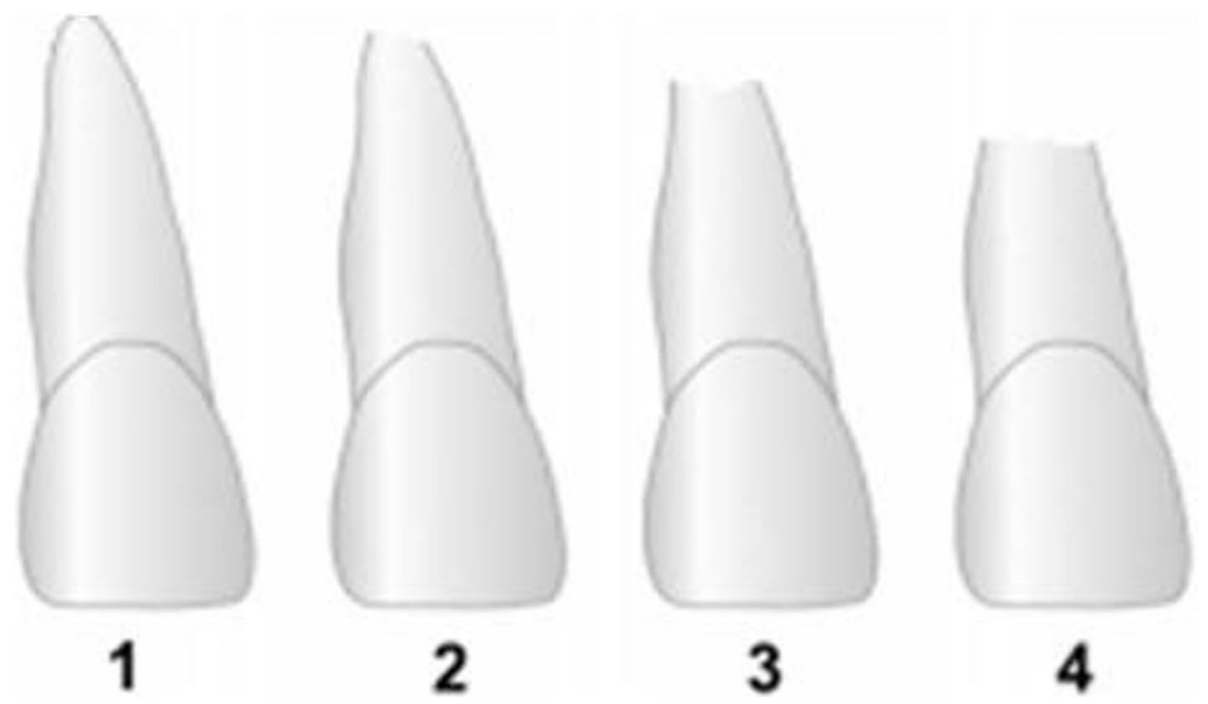

Fig. 2 External apical root resorption (EARR) stages according to Malmgren et al. 1 irregular root contour, 2 EARR $<2$ mm of root length, 3 EARR $>2 \mathrm{~mm}$ to $1 / 3$ of root length, 4 EARR $>1 / 3$ of root length. This figure was first described by Jacobs et al. Head \& face medicine 2014,10:2

finished with $0.019 \times 0.025$-in stainless steel in conventional group. The archwire sequence for the self-ligating group included 0.014-in, a $0.014 \times 0.025$-in copper-nickel-titanium Damon (Ormco) and finished with $0.019 \times$ 0.025-in stainless steel. All the patients were treated by the same clinician who has received training in both appliance systems.

The panoramic radiographs were taken before and after treatment with the same radiographic machine (SIEMENS, SIDEXIS XG, Germany) and by the same operator.

\section{$\mathrm{X}$-ray measurement and patient informed consent} Correction Factor $(\mathrm{CF})=\mathrm{C} 1 / \mathrm{C} 2$.

$\mathrm{C} 1=$ Crown length on pretreatment radiograph

$\mathrm{C} 2$ = Crown length on post-treatment radiograph

The measurement of EARR as following.

$\mathrm{R} 1$ = Root length before treatment

$\mathrm{R} 2$ = Root length after treatment

The relative root resorption (rRR) which seen as the percentage shortening per tooth was used to represent the EARR, see Fig. 1.

Quantitative measurements of the crown and root length of the maxillary central and lateral incisors were taken. The crown length registrations was used to assess the image distortion between the before and after treatment radiographs. Linge and many other study had described this measurement method in previous studies [13, 14] (Fig. 2).

The calibrated panoramic radiographs were used to measure incisor root lengths before and after treatment. All patients were informed about the purpose of this research and given their informed consent.

\section{Statistical assessment}

The pair-T or chi-square test were conducted to examine the difference between two groups. The multiple regression models were used to investigate the factors of EARR, such as gender, age, and treatment duration. The significance level was set at 0.05 . All statistical analyses were performed using SPSS 20.0 (SPSS Inc., Chicago IL, USA).

\section{Error determination}

According to Dahlberg's formula [15], 20 panoramic radiographs were randomly retraced and were re-measured 2 months after the first assessment to determine systematic error. The error results fell within a very good range of $(0.12 \mathrm{~mm})$.

\section{Results}

Table 2 shows the baseline information of 2 appliance groups. There was no significance difference in baseline information between the two appliance groups.

Table 3 The degree of root resorption ( $\mathrm{mm}$ ) between T1 and T2 for the patients in self-ligating brackets group

\begin{tabular}{llllllllll}
\hline Measurements, $\mathrm{mm}$ & $\mathrm{T} 1$ & & & $\mathrm{~T} 2$ & & $\mathrm{~T} 2-\mathrm{T} 1$ & $\mathrm{P}$ \\
\cline { 2 - 3 } & Mean & $\mathrm{SD}$ & & Mean & $\mathrm{SD}$ & & \\
\hline Maxillary right central incisor & 25.23 & 1.58 & & 24.91 & 1.28 & -0.32 & 0.001 \\
Maxillary right lateral incisor & 24.35 & 1.26 & & 24.08 & 1.22 & -0.27 & 0.001 \\
Maxillary left central incisor & 25.25 & 1.54 & 24.92 & 1.32 & -0.33 & 0.004 \\
Maxillary left lateral incisor & 24.27 & 1.25 & 23.99 & 1.35 & -0.28 & 0.001 \\
\hline
\end{tabular}


Table 4 The degree of root resorption $(\mathrm{mm})$ between T1 and T2 for the patients in conventional preadjusted brackets group

\begin{tabular}{llllllllll}
\hline Measurements, $\mathrm{mm}$ & $\mathrm{T} 1$ & & & $\mathrm{~T} 2$ & & & \\
\cline { 2 - 3 } & Mean & $\mathrm{SD}$ & & Mean & $\mathrm{SD}$ & T2-T1 & $\mathrm{P}$ \\
\hline Maxillary right central incisor & 25.26 & 1.26 & & 24.86 & 1.18 & -0.40 & 0.002 \\
Maxillary right lateral incisor & 24.52 & 1.32 & & 24.17 & 1.29 & -0.30 & 0.007 \\
Maxillary left central incisor & 25.22 & 1.52 & & 24.83 & 1.24 & -0.39 & 0.001 \\
Maxillary left lateral incisor & 24.54 & 1.26 & 24.23 & 1.35 & -0.31 & 0.005 \\
\hline
\end{tabular}

In Table 3, all teeth occurred root resorption and reached a statistically level after treatment in group I. In Table 4, we can see that the same situation in Group II. However, in Table 5, there was no statistically significant difference was found between the two groups in the degree of root resorption.

In Table 6, we found that self-ligating bracket group had $49 \%$ and conventional bracket group had $35 \%$ of the teeth classified with scores of 0 and 1 . When refer to the score of 2 to 4 , group 1 had $51 \%$ and group 2 had $65 \%$.

Table 7 showed that EARR increased when treatment duration increased by using univariate analysis. Multivariate regression showed that treatment duration was significant risk factors of EARR. Extension of treatment time by 1 month will lead to root absorption of 0.05 $\mathrm{mm}$. Compared to self-ligating brackets, conventional appliances induced more EARR with an average of 0.35 $\mathrm{mm}$ when take treatment duration effects into accounting (Table 7).

\section{Discussion}

In this study, we are aimed to investigate the amount of EARR and the occurrence of EARR on maxillary incisors in extraction patients between SL and Non-SL brackets. We found that there is no difference in the amount of EARR between conventional and passive self-ligating brackets group. To our best knowledge, this is the first study which only included extraction patients to assess the amount of EARR between conventional and passive self-ligating brackets. In the previous studies [9-11], they were included patients with or without extraction when assess the occurrence of EARR. We all know that patients with tooth extraction are more prone to root

Table 5 The Difference in Root resorption between Self-ligating brackets and conventional brackets group

\begin{tabular}{|c|c|c|c|c|c|}
\hline \multirow[t]{2}{*}{ Measurements, mm } & \multicolumn{2}{|c|}{$\begin{array}{l}\text { Self-ligating } \\
\text { Brackets Group }\end{array}$} & \multicolumn{2}{|c|}{$\begin{array}{l}\text { Conventional } \\
\text { Brackets Group }\end{array}$} & \multirow[t]{2}{*}{$P$} \\
\hline & Mean & SD & Mean & SD & \\
\hline Maxillary right central incisor & -0.32 & 0.24 & -0.40 & 0.28 & NS \\
\hline Maxillary right lateral incisor & -0.27 & 0.28 & -0.30 & 0.25 & NS \\
\hline Maxillary left central incisor & -0.33 & 0.27 & -0.39 & 0.31 & NS \\
\hline Maxillary left lateral incisor & -0.28 & 0.25 & -0.31 & 0.26 & NS \\
\hline
\end{tabular}

Table 6 Distribution of teeth with apical root resorption

\begin{tabular}{|c|c|c|c|c|}
\hline \multirow{2}{*}{ Score } & \multicolumn{2}{|c|}{ Self-ligating Brackets Group } & \multicolumn{2}{|c|}{ Conventional Brackets Group } \\
\hline & $n$ & $\%$ & $n$ & $\%$ \\
\hline 0 & 4 & 8 & 5 & 10 \\
\hline 1 & 20 & 41 & 12 & 25 \\
\hline 2 & 18 & 37 & 20 & 41 \\
\hline 3 & 4 & 8 & 7 & 14 \\
\hline 4 & 3 & 6 & 5 & 10 \\
\hline
\end{tabular}

resorption than those without tooth extraction [16-18]. It is not wise to combine the extraction and non-extraction patients for analysis in one study.

Compare to the previous studies, in this study, all patients were treated by one orthodontist with the similar sequence of changing archwires. This guarantees a good comparability between the two groups. Furthermore, we recruited more patients than previous studies, which may display a higher value of significance [9-11].

This study only included maxillary incisors because maxillary incisors were most susceptible to root resorption during orthodontic treatment. The results of this study found that an average of $0.3 \mathrm{~mm}$ and $0.35 \mathrm{~mm}$ root resorption in conventional bracket and self-ligating group groups, respectively. Other studies found the average of root resorption were range from $0.53 \mathrm{~mm}$ to 0.76 $\mathrm{mm}$ in fixed appliance [19-22]. The reason may be the different measure method and the included different patients.

Compared with conventional brackets, it has been hypothesized that fast tooth movement in self-ligating brackets will result in more EARR during the orthodontic treatment $[23,24]$. However, in this study, we found that there was no statistically significant difference between conventional and self-ligating brackets group in EARR. Multivariate regression also showed that appliance type was not significant risk factors of EARR. Others studies also confirmed the same results that self-ligating brackets did not lead to the higher rate of EARR [9-12].

Table 7 Predictor factors for root resorption $(\mathrm{mm})$ as dependent variable by using univariate and multivariate model

\begin{tabular}{|c|c|c|c|c|c|c|c|}
\hline \multirow{2}{*}{$\begin{array}{l}\text { Predictor } \\
\text { variables }\end{array}$} & \multirow[t]{2}{*}{ Category } & \multicolumn{3}{|c|}{ Univariate model } & \multicolumn{3}{|c|}{ Multivariate model } \\
\hline & & $\mathrm{b}$ & SE & $P$ value & $\mathrm{b}$ & SE & $P$ value \\
\hline \multirow[t]{2}{*}{ Appliance } & Conventional & baseline & & & baseline & & \\
\hline & Self-ligating & 0.42 & 0.22 & NS & 0.35 & 0.16 & 0.04 \\
\hline $\begin{array}{l}\text { Treatment } \\
\text { duration }\end{array}$ & 1 month & 0.05 & 0.01 & 0.03 & 0.05 & 0.04 & 0.02 \\
\hline \multirow[t]{2}{*}{ Sex } & Female & baseline & & & & & \\
\hline & Male & 0.32 & 0.45 & NS & & & \\
\hline Age & 1 year & 0.24 & 0.18 & NS & & & \\
\hline
\end{tabular}


There was no significance difference between two groups in relative severe root resorption, but the number of severe root resorption was less in self-ligating brackets than conventional brackets group. The explanation may be due to the continuous light force provided by the self-ligating brackets. Light forces have long been recommended to reduce adverse tissue reactions, such as root resorption [25].

In this study, we are interested to find that treatment during is a predictor factor of EARR when receive the orthodontic treatment. We are even further come to a conclusion that extension of treatment time by 1 month will lead to root absorption of $0.05 \mathrm{~mm}$. The reason may be extended tooth movement will result in persistent bone turnover which may cause more root resorption [26]. Others also found the treatment duration had a positive association with the amount of EARR $[27,28]$.

Some deficiencies still need to draw our attention. First, the panoramic radiographs is not precise than periapical radiographs or CBCT for measuring EARR [29]. However, taking into account that the higher radiation dose of the periapical radiographs or $\mathrm{CBCT}$, and many studies have confirmed that it is possible to use a panoramic film to initially determine the amount of root absorption [30-32]. Second, although we strictly matched the treatment group and the control group when selecting cases, it may be difficult to avoid the influence of confounding factors on the results. It is better to adopt randomize design to compare the EARR between the two type brackets in the future. At last, we still need to include more different ethnic patients to verify whether the two brackets influence the root resorption.

\section{Conclusions}

There was no statistically significant difference in the occurrence of EARR and the amount of EARR between conventional and passive self-ligating brackets in class I extraction patients.

\section{Abbreviations}

EARR: External apical root resorption; SL: Self-ligating bracket

\section{Acknowledgements}

The authors would like to thank Ms. Ramona Menden for her valuable support.

\section{Funding}

No funding was received for this publication.

\section{Availability of data and materials}

The datasets used and/or analyzed during the current study are available from the corresponding author on reasonable request.

\section{Authors' contributions}

QF made substantial contributions to the papers conception and were involved in drafting the manuscript. ZY was responsible for revising it and for getting final approval of the version to be published. Both authors read and approved the final manuscript.
Ethics approval and consent to participate

Not applicable.

\section{Consent for publication}

Not applicable.

\section{Competing interests}

The authors declare that they have no competing interest.

\section{Publisher's Note}

Springer Nature remains neutral with regard to jurisdictional claims in published maps and institutional affiliations.

\section{Author details \\ ${ }^{1}$ Department of Stomatology, Shaoxing People's Hospital, Shaoxing, China. ${ }^{2}$ Department of Orthodontic, School and Hospital of Stomatology, Wenzhou Medical University, Wenzhou, Zhejiang, China.}

Received: 9 May 2018 Accepted: 19 March 2019

Published online: 29 March 2019

\section{References}

1. Artun J, Smale I, Behbehani F, Doppel D, Van't Hof M, Kuijpers Jagtman AM. Apical root resorption six and 12 months after initiation of fixed orthodontic appliance therapy. Angle Orthod. 2005;75:919-26.

2. Fleming SP, Dibiase AT, Lee RT. Randomized clinical trial of orthodontic treatment efficiency with self-ligating and conventional fixed orthodontic appliances. Am J Orthod Dentofac Orthop. 2010;137:738-42.

3. Linge $L$, Linge BO. Patient characteristics and treatment variables associated with apical root resorption during orthodontic treatment. Am J Orthod Dentofac Orthop. 1991;99:35-43.

4. Mirabella AD, Årtun J. Prevalence and severity of apical root resorption in upper anterior teeth in adult orthodontic patients. Eur J Orthod. 1995;17:939.

5. Sameshima GT, Sinclair PM. Predicting and preventing root resorption: part I. Diagnostic factors. Am J Orthod Dentofac Orthop. 2001;119:505-10.

6. Baumrind S, Korn EL, Boyd RL. Apical root resorption in orthodontically treated adults. Am J Orthod Dentofac Orthop. 1996;110:311-20.

7. Harris EF, Baker WC. Loss of root length and crestal bone height before and during treatment in adolescent and adult orthodontic patients. Am J Orthod Dentofac Orthop. 1990;98:463-9.

8. Beck BW, Harris EF. Apical root resorption in orthodontically treated subjects: analysis of edgewise and light wire mechanics. Am J Orthod Dentofac Orthop. 1994;105:350-36.

9. Leite V, Conti AC, Navarro R, Almeida M, Oltramari-Navarro P, Almeida R. Comparison of root resorption between self-ligating and conventional preadjusted brackets using cone beam computed tomography. Angle Orthod. 2012;82:1078-82.

10. Liu XQ, Sun $X L$, Yang Q, Fan CH, Chen XJ. Comparative study on the apical root resorption between self-ligating and conventional brackets in extraction patients. Shanghai J Stomatol. 2012;21:460-5.

11. Chen W, Haq AA, Zhou Y. Root resorption of self-ligating and conventional preadjusted brackets in severe anterior crowding class I patients: a longitudinal retrospective study. BMC Oral Health. 2015;15:115.

12. Blake M, Woodside DG, Pharoah MJ. A radiographic comparison of apical root resorption after orthodontic treatment with the edgewise and speed appliances. Am J Orthod Dentofac Orthop. 1995;108:76-84.

13. Linge $B O$, Linge $L$. Apical root resorption in upper anterior teeth. Eur J Orthod. 1983:5:173-83.

14. Jacobs C, Gebhardt PF, Jacobs V, Hechtner M, Meila D, Wehrbein H. Root resorption, treatment time and extraction rate during orthodontic treatment with self-ligating and conventional brackets. Head Face Med. 2014;23(10):2.

15. Hikita Y, Yamaguchi T, Tomita D, Adel M, Nakawaki T, Katayama K, Maki K, Kimura R. Relationship between tooth length and three-dimensional mandibular morphology. Angle Orthod. 2018;88:403-9.

16. Iglesias-Linaresa A, Sonnenbergb B, Solanob B, Yañez-Vico R-M, Solanod E, Lindauere SJ, Flores-Mir C. Orthodontically induced external apical root resorption in patients treated with fixed appliances vs removable aligners. Angle Orthod. 2017:87:3-10.

17. Marcio RA, Aline SB, Thais MF, Juliana BV, Renato R, Ravindra N. A comparative study of the effect of the intrusion arch and straight wire 
mechanics on incisor rootresorption: a randomized, controlled trial. Angle Orthod. 2018;88:20-6.

18. Carlos EN, Andreia CF, Ana C, Danilo PV, Mauricio AC, Renata Rodrigues AP. Comparative study of root resorption of maxillary incisors in patients treated with lingual and buccal orthodontics. Angle Orthod. 2017;87:795-800.

19. Artun J, Smale I, Behbehani F, Doppel D, Van't Hof M, Kuijpers-Jagtman AM. Apical root resorption six and 12 months after initiation of fixed orthodontic appliance therapy. Angle Orthod. 2005;29:919-26.

20. Janson GR, De Luca CG, Martins DR, Henriques JF, De Freitas MR. A radiographic comparison of apical root resorption after orthodontic treatment with 3 different fixed appliance techniques. Am J Orthod Dentofac Orthop. 1999;118:262-73.

21. Alexander SA. Levels of root resorption associated with continuous arch and sectional arch mechanics. Am J Orthod Dentofac Orthop. 1996;110: $321-4$.

22. Mavragani M, Vergari A, Selliseth NJ, Boe OE, Wisth PJ. A radiographic comparison of apical root resorption after orthodontic treatment with a standard edgewise and a straight-wire edgewise technique. Eur J Orthod. 2000;22:665-74.

23. Sumit $Y$, Thomas $D$, Amir A, Zana K, Ravindra N. The effect of mechanical vibration on orthodontically induced root resorption. Angle Orthodontist. 2016:86:740-5

24. Weltman B, Vig KW, Fields HW, Shanker S, Kaizar EE. Root resorption associated with orthodontic tooth movement: a systematic review. Am J Orthod Dentofac Orthop. 2010;137:462-76.

25. Chan E, Darendeliler MA. Physical properties of root cementum: part 5 . Volumetric analysis of root resorption craters after application of light and heavy orthodontic forces. Am J Orthod Dentofac Orthop. 2005;127:186-95.

26. Sameshima GT, Asgarifar KO. Assessment of root resorption and root shape: periapical vs panoramic films. Angle Orthod. 2001;71:185-9.

27. Makedonas D, Lund H, Gröndahl K, Hansen K. Root resorption diagnosed with cone beam computed tomography after 6 months of orthodontic treatment with fixed appliance and the relation to risk factors. Angle Orthod. 2011;139:e73-81.

28. Smale I, Artun J, Behbehani F, Doppel D, Van't Hof M, Kuijpers-Jagtman AM. Apical root resorption 6 months after initiation of fixed orthodontic appliance therapy. Am J Orthod Dentofacial Orthop. 2005;128:57-67.

29. Yi J, Sun Y, Yu L, Li C, Li X, Zhao Z. Cone-beam computed tomography versus periapical radiograph for diagnosing external rootresorption: a systematic review and meta-analysis. Angle Orthod. 2017;2:328-37.

30. Ballard DJ, Jones AS, Petocz P, Darendeliler MA. Physical properties of root cementum: part 11. Continuous vs intermittent controlled orthodontic forces on root resorption. A microcomputed-tomography study. Am J Orthod Dentofacial Orthop. 2009:136:8.e1-8.

31. van Leeuwen EJ, Maltha JC, Kuijpers-Jagtman AM. Tooth movement with light continuous and discontinuous forces in beagle dogs. Eur J Oral Sci. 1999;107:468-74

32. Aras B, Cheng LL, Turk T. Physical properties of root cementum: part 23 . Effects of 2 or 3 weekly reactivated continuous or intermittent orthodontic forces on root resorption and tooth movement: a micro-computed tomography study. Am J Orthod Dentofac Orthop. 2012;141:e29-37.

Ready to submit your research? Choose BMC and benefit from:

- fast, convenient online submission

- thorough peer review by experienced researchers in your field

- rapid publication on acceptance

- support for research data, including large and complex data types

- gold Open Access which fosters wider collaboration and increased citations

- maximum visibility for your research: over $100 \mathrm{M}$ website views per year

At $\mathrm{BMC}$, research is always in progress.

Learn more biomedcentral.com/submissions 